To the paper

\title{
ERRATA
}

\section{Determination of molybdenum and uranium in biological materials by radiochemical neutron activation analysis}

\author{
B. Danko, R. Dybczyński \\ Institute of Nuclear Chemistry and Technology, ul. Doradna 16, 03-195 Warszawa, Poland
}

appeared in the Journal of Radioanalytical and Nuclear Chemistry, 216, No. 1 (1997) 51-57.

On page 56, in Table 2, the uranium content should read $16.1 \pm 2.4$ instead of $161.1 \pm 2.4$.

To the paper

\section{Carbon-13 intermolecular isotope effect in the decarbonylation of liquid extra pure Merck formic acid}

\section{Zielińnski," A. Zielińska,* S. Bernasconi,"* H. Papiernik-Zielińska*}

*Isotope Laboratory (Laboratory of Nuclear Chemistry), Faculty of Chemistry, Jagiellonian University, Kraków, Poland

**Laboratory of Stable Isotope (Geologisches Institut), ETH (Swiss Federal Institute of Technology), Zürich, CH.8092 Zürich, Switzerland

appeared in the Journal of Radioanalytical and Nuclear Chemistry, 220, No. 2 (1997) 263-265.

The sign "In" was written unnecessarily before Eyring Equation (5) on p. 265. The Equation (5) should be written as: $\left(k_{\exp } / T\right)=\left(k_{B} / \mathrm{h}\right) \exp \left(\Delta S^{\ddagger} / R\right) \exp \left(-\Delta H^{*} / R T\right)$. 